ence equal to that between Greenwich and Montpellier in the south of France-a difference which might possibly arise from extraordinary and diverse ocean-currentsbut to such a supposition current charts give no support. The publication might be rendered even still more useful by including among the means those of the maxima and minima of temperature, and those at the hours of 9 A.M. and 3 P.M. for pressure and temperature at all the stations, and by indicating on the map the whole of the stations from which observations are given in each year's publication.

\section{AMERICAN-INDIAN STONE TUBES AND TOBACCO-PIPES}

DRING the summer of I 873 , I found a single specimen of a stone tube, that had been split throughout its entire length, as seen in Fig. 1. Since then, I have had an opportunity of examining several specimens found in New Jersey, and fortunately found two in the locality of my principal labours, in gathering up the scattered relics of the aborigines.

$\mathrm{Fi}$. I is made of beautiful veined green and black slate, is six and one-eighth inches in length, slightly oval, and has been highly polished. The bore, which is exactly half-aninch in diameter, is circular, unifo-m and direct. The drilling has evidently been accomplished by the use of a reed with sand and water, and the circular striae are visible throughout the length of the perforation. This drilling is the more interesting from the fact, that the work, commenced at one end, has been continued to the other, and not from either end to the middle, which latter method (and much the more common one) produces an hour-glass contraction at the point of juncture of the two drillings. Six or seven inches, however, was not the maximum depth at empted at driling in ove direction. Prof. Wyman, in "

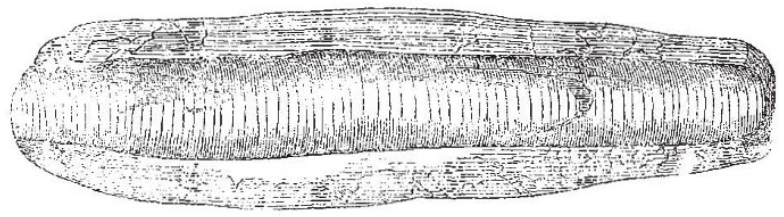

FIG. 1.-One-half natural size.

p. 13, describes "a cylindrical tube of soap-stone, twentytwo inches long and two inches in diameter, tapering somewhat at either end. This had been drilled from opposite ends, but the two perforations not coinciding, they passed by each other, the bores communicating laterally." We have in this implement, therefore, a single bore at least twelve inches long; which is probably the maximum length, for it is difficult to conceive of a stone to be of greater length than two feet, being of any use. ${ }^{I}$ This is about the maximum of the non-perforated cylindrical stones called pestles; but which probably had other uses than that name implies.

Fig. 2, represents a quite common form of ornamental stone implement, but which, unfortunately, are seldom found except in very fragmentary condition. This specimen measures six and seven-eighths inches in length, by eight inches, lacking three-sixteenths, in breadth. The mineral is a soft sandstone, smoothed but not polished, and free from all attempt at ornamenration. Such specimens, when of less dimensions, bave ordinarily been classed as badges of authority, gorgets, or if narrower, as double-edged axes, which could never have been their use, considering the soft material of which they are invariably

" Mr. Evans, in his "Ancient Stone Implements of Great Britain," remarks that "the tubes of steatite one foot in length found in some of the minor mounds of the Ohio Valley, must probably have been bored with meral "This depends altogether upon their age New Jersey specimen of tubes have been found of nearly that length, which undoubtedly were made before the introduction of metal. made. As the perforation of this specimen exceeds in length that of the preceding, I am led to consider this simply as a "winged" tube, and to have had a use identical with such as above described (Fig. I). While cylindrical tubes, plain or onamented, are quite abundant in

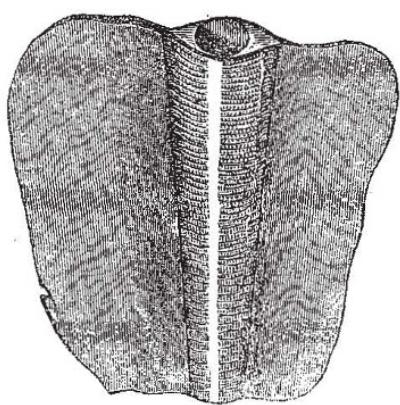

FIG. 2.-One-fifth natural size.

the southern and western states, these winged tubes appear to replace them in the northern and mid fle states.

Figs. 3 and 4 represent two specimens of tubes, that are of much interest, in that, while of the same general character as the preceding, they have not been bored; but are made of clay which has been moulded when soft, about a straight cylinder, presumably of wood, and then baked very hard. The exposure to fire would necessarily char, if not consume, the encased wood, and so leave a perforation in the clay when baked. This tube has then been brought to its present shave by scraping, and the ornamentation lastly carved upon it. In both specimens, the projective figure has been broken off, but the remaining fragment in Fig. 3 suggests the figure of a mammal, and that of Fig, 4 possibly a human head. On the tube, Fig. 3, will be noticed fi. e short parallel lines. Such rows

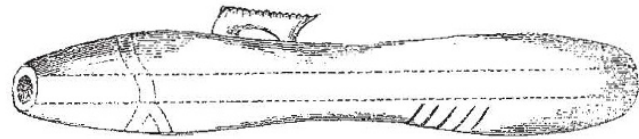

Fig. 3.-Une-third natural size.

of short deeply engraved lines are very characteristic of the relics found in New Jersey (see figure of Marriage Emblem in NATURE, vol. xi., p. 436), and are probably record marks, but of what, on an implement like this, it is difficult to conjecture. The general shape of these tubes, and their diameters render it quite certain that they are not simply the stems of clay smoking-pipes.

These two specimens were found in the same grave, associated with the ordinary weapons of the aborigines; axes, spears, and arrow-points.

Fig. 5 represents a stone tube of a pattern quite different from any of the preceding. It is made of very soit soap-stone, is quite smooth, and accurately outlined. It is four and three-fourths inches in length; one and onefourth inches in width at the broad, trumpet-mouthed enc, and half-an-inch in diameter, where broken. The

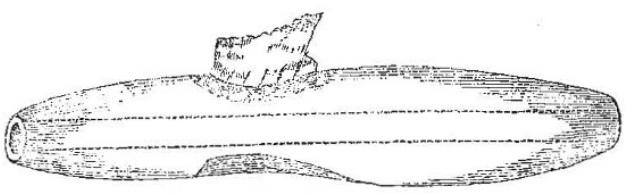

Fig. 4.--One-ihird natural size.

perforation is one-iourth of an inch in diameter, and of uniform size throughout. Such trumpet-shaped specimens occur elsewhere. Prof. Jeffries Wyman describes one in the Report above quoted, same page. He writes: "A fragment of another tubular instrument of the same ma- 
terial (soap-stone) appears to have had a long cylindrical body, and ends in an enlarged and trumpet-shaped mouth, and possibly was used as a horn."

Fig. 5 has faintly engraved upon it a serpent, or what appears to have been one. This representation of a serpent, and the figures on the specimens, Nos. 3 and 4 , have probably the same object. Either they represent the owner, the name of the object being that of the possessor of the tube; or, if they were used solely by the sorcerers as "medicine tubes," 1 wherewith they blew away disease, then the serpent in the one case, and the figures, now undeterminable, on Figs. 3 and 4, were the "gods" or "devils," through whose inspiration the "doctors" effected their cures. How to explain the meaning of the "wings," of Fig. 2 , is certainly difficult, if I am corr ect in my surmises concerning the other specimens; but these may simply be meaningless ornamentation, just as the broken specimen, Fig. I, when entire, was just as effectual as any in Llowing away disease, provided the suffering patient was made to believe so, by entertaining faith in his physician.

A few words in conclusion upon the use of stone drills in boring through stone. There is, in the museum of the Peabody Acadimy at Salem, Massachusetts, several hundred specimens of stone-drills, all of jasper, and varying greatly in length. These specimens, collected by the writer, have been frequently experimented with, and they are found capable of very rapidly drilling in the minerals of which these tubes and "gorgets" usually are made. And when sand and water are used in addition, it is not extremely difficult to drill in mineral of like or greater density. Stone-drills, such as here referred to, are not flat, like a slender arrow-point, but quadrangular (diamondshaped) when viewed in section. The points of the few

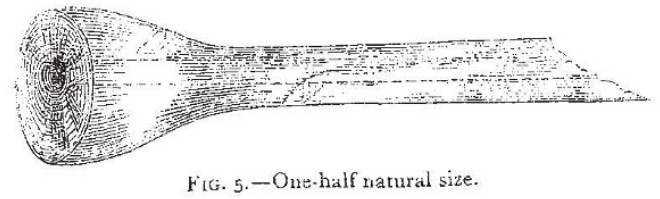

perfect specim $\mathrm{ns}$ I have found, were mostly very highly polished, and the sides showed clearly, in some specimens, polished, and sand. These drills vary from one to seven inches in length, and fiom three-sixteenths to over an inch in diameter; or rather the bores they made, had these measurements. Figures of such drills are given in vol. vi. of "American Naturalist," pp. 205-2I4; also by $M r$ Evans, in "Ancient Stone Implements of Great Britain", p. 290, Fig. 23o. None of the drills, however, mentioned by Mr. Evans, are large, and are capable only of perforating thin plates of stone. While convinced that a reed, with sand and water was most frequently used in deep borec, I can see no reason for doubing that stone-drills were also used; for such specimens are by no means rare, and no other use can be suggested for them.

The various torms of stone implements found in $\mathrm{New}$ Jersey, however specialised, appear to be all traceable to others, far less elaborate, and these ruder patterns, as I have endeavoured to show, are now found at such depths, as a mile, that they may safely be considered as of greater antiquity and the forerunners of the more finished types, the true surface-found specimens. From this fact I have concluded that the red man of the Atlantic this fact North America reached our shores a palæolithic savage, and when discovered by the Europeans had attained to the neolithic stage of culture.

There is one form of stone implement (and only one) that ofiers an exception to the assumed rule that the rucier antedate the more finished sptcimens; that is, the

$x$ Venegas (Nat. and Civil Hist. of California, vol. i., p. 97. London, 7759) states: "Thev (medicine men) applied to the suffering part of the patient's body the chacuaco, or a tube of a very hard bleck stone; and patient's body they som-times sucked, and other times blew." Quoted by c. C. Jones, junr., in "Antiquities of Suuthesn Irdians," p. 363 . smoking pipes. There are no rude or palæolithic pipes occurring in New Jersey, nor, I believe, in any portion of the country. They are all more or less polished and so wrought that they must be classed as a neolithic form of stone implement. Among the chipped unpolished implements of the river gravels I have been unable to find any specimen that could be imagined even to be connected with the custom of smoking. There is, however, abundant evidence of improvement in the flint-chipping art having been attained by the red man while an occupant of this country, readily traced in the axes, arrowpoints, and other forms of weapons and domestic implements; and such advance is not seen in the fashioning of pipes.

For the reasons already stated, I conclude that the custom of tobacco smoking was introduced or established after the red man had attained to the higher division of the Stone age; and that the first pipes were of perishable materials. Such pipes must, I think, have been of wood. Succeeding the use of this, which was necessarily inconvenient, there is reason to believe that a rude clay bow was attached to the stem, a mere shapeless lump of clay that they would soon learn was rendered somewhat more durable by the exposure to heat. The use of clay bowls might have arisen, too, by the hardening of the earth simply, if the first receptacle for the tobacco was simply a depression in the ground, to the bottom of which was

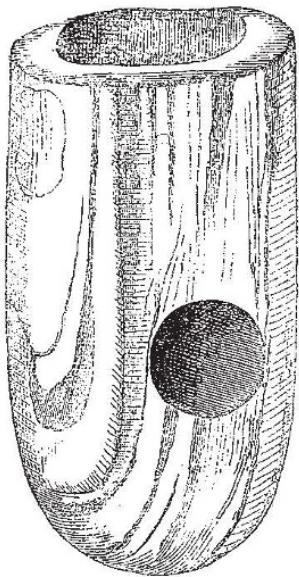

Fig. 6.--Plain Pipe Bowl, natural size.

placed one end of the reed, through which the smoke was drawn to the mouth. However this might have been, I believe I have found fragments of pipes so rude in their shape and coarse in their composition as to warrant the belief that such specimens were the forerunners of the durable stone pipes that now occur in scanty numbers among the relics of the red men of New Jersey.

Inasmuch as the use of clay for pipe bowls was no: abandoned, there of course exists a vast range of excellence in the workmanship displayed in their manufacture, and many of the fragments that I have found were as artistically ornamented and made of as carefully prepared clay as others were rude and of the coarsest material. These rudest specimens are never found in graves, and seldom met with except when deeply embedded in the soil, suggesting that they were in use before the custom of burying the smoking pipes of the dead with them was established, and therefore that they antedate the more elaborately finished specimens, which are occasionally found among the deposited relics of "grave-finds;" but such an occurrence is rare in comparison with the presence of stone pipes under similar circumstances.

While the pipe bowls of stone exhibit $\dot{a}$ considerabie range in the excellence of their finish, there is not sufficient variation to warrant one in considering the more rudely finished specimens as the older. They are all well 
made and admirably adapted to their peculiar use. Ornamentation was confined, in the vast majority of cases, to the natural markings of the mineral, and not derived from any carving as is so marked a characteristic of the pipes of the mound-builders. Fig. 6 represents a perfect specimen of such plain pipe bowls as I have described. There is no line, straight, curved, or zigzag upon it. The red man who made this specimen had utility solely in view ; unless the choice of mineral was considered, as giving beauty to the finished pipe. The material of the specimen figured is a pale green slaty rock, veined with black. The variation in shape of such pipe bowls is of course considerable; and supposing each individual to have made his own pipe, the shape was in each case decided by the maker's fancy solely. As in the case of arrow. points, of which a score of patterns occur, so with pipe bowls. One will scarcely find two precisely alike; yet the "family likeness" is very strongly marked.

There does occur, however, a second form of smoking pipe, but much more sparingly than the preceding, differing greatly, both in size and shape. While the two patterns occasionally approach in general outline, they do not do so sufficiently to warrant our considering the one to pass into the other form.

This variety of pipe, of which Fig. 7 is an example, is well known as the calumet or "peace-pipe." The bowl

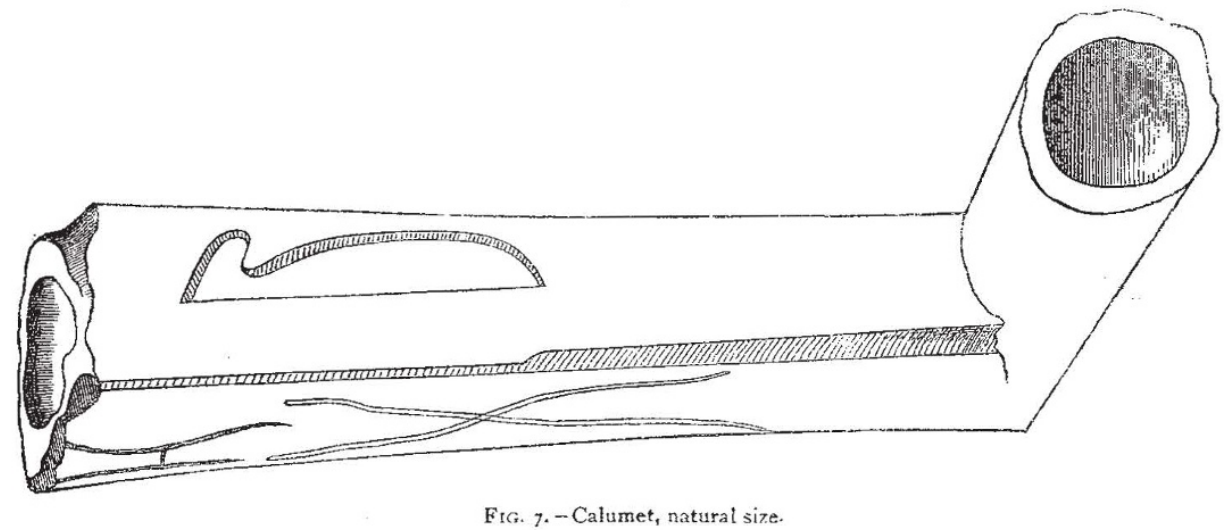

in this case, as a rule, is much smaller, and the labour of the maker has been expended upon the stem-like base, which in every specimen I have seen has been quite elaborately ornamented. The specimen figured is not as much carved as many, but being quite perfect, is represented in preference to fragments of others.

I believe no specimens of " animal pipes," such as are found in the Mississippi valley, have been found in New Jersey, which fact is interesting, as there is much reason for believing that when the mound-builders occupied the western valleys the red man was already occupying the Atlantic coast; and doubtiess some trading was carried on between the two peoples. Therefore, it would be natural to expect that such pipes should occur among our Indian relics; or at least that there was sufficient knowledge concerning them to suggest to the coast Indians the idea of imitating them; but there is no trace of such imitation I believe. It is their smoking pipes alone, of all their productions in the flint-chipping art, that are dissimilar.

Through the writings of the earlier missionaries we learn of the peculiar uses and significance of these calumets, which formed so prominent a feature on all important occasions; but whether they were introduced by some other race with whom the red man came in contact, or originated de novo, it is impossible to determine; but it is quite certain that the specimens so far brought to light do not enable us to trace the evolution of the calumet from the simpler form of pipe.

Trenton, N.J., U.S.A., May 6 Chas. C. AвBOtr

\section{NEW METEOROLOGICAL LABORATORIES AT MONTSOURIS}

M MARIÉ DAVY, Director of Montsouris ObservaN. tory, has organised, partly at the expense of the French Government, partly at the expense of the City of Paris, a chemical and microscopical laboratory for the analysis of all the matters in suspension in the air of Paris, both quantitatively and qualitatively. A certain quantity of air is constantly aspired by an aspirator in continued operation. The ozone acting on iodide of potassium and starch liberates iodine. The quantity of nzone liberated is measured by a titrated solution of arsenite of sodium. The matters in suspension are collected on a glass plate, and the crop is placed under the ebject-glass of a powerful microscope magnifying $\mathrm{I}, \infty 00$ times. The principal forms are drawn and plates are executed and published monthly in the Transactions of the establishment. The analysis of rain-water is conducted on the same principles, and the results of chemical analysis are calculated and compared with the wind and other atmospheric circumstances.

We are indebted to M. Marié Davy for the principal results of the month of February, the first period for which the whole system has been put into complete operation.

The electrical department has been fitted up, after a preliminary trial, and has been in working order for some time. In orcer better to illustrate the importance of these researches we take the liberty of altering the figures in order to give the results in round numbers for the whole area of Paris within the fortifications. The surface is about $80,000,000$ square metres. In February 1876 the quantity of atmospheric water was $4,500,000$ cubic metres. This is about double the average, but in some years on record the quantity was even larger, in 1776 a century ago, it was more than $6,500,000$ cubic metres. In taking as an average the analyses of rain-water at Montsouris, the 4,500,000 cubic metres contained 4,700 kilogrammes of nitric acid and 10,700 kilogrammes of ammonia. This mass of nitric acid is supposed to have been produced by electrical reactions in the atmosphere, and ammonia only partly, as Montsouris is in the southern part of the city, close to the fortifications.

The 4,500,000 cubic metres of rain water were also proved to contain 172,000 kilogrammes of organic matter, and 88,400 kilogrammes of metallic salts or products. A number of organic matters have been found 